\title{
The Safety Profile of Vedolizumab in Ulcerative Colitis and Crohn's Disease: 4 Years of Global Post-Marketing Data
}

\section{Russell D. Cohen, ${ }^{\text {a }}$ Fatima Bhayat, ${ }^{\mathrm{b}}$ Aimee Blake, ${ }^{\mathrm{b}}$ Simon Travis ${ }^{\mathrm{c}}$}

a Department of Medicine, Inflammatory Bowel Disease Center, University of Chicago Medicine, Chicago, IL, USA

${ }^{\mathrm{b}}$ Takeda Pharmaceuticals International Co., Cambridge, MA, USA

${ }^{\mathrm{c}}$ Translational Gastroenterology Unit, National Institute for Health Research Oxford Biomedical Research Centre, Oxford University Hospitals NHS Foundation Trust, John Radcliffe Hospital, Oxford, UK

Corresponding author:

Russell Cohen, Department of Medicine, Inflammatory Bowel Disease Center, University of Chicago Medicine, Chicago, IL, USA

Office tel: 1-773-702-0719

Office fax:1-773-702-2182

E-mail: rcohen@medicine.bsd.uchicago.edu

Short title: Vedolizumab safety in IBD: 4yrs post-marketing use 
Non-standard abbreviations:

$\begin{array}{ll}\text { AE } & \text { adverse event } \\ \text { CD } & \text { Crohn's disease } \\ \text { GI } & \text { gastrointestinal } \\ \text { HIV } & \text { human immunodeficiency virus } \\ \text { IBD } & \text { inflammatory bowel disease } \\ \text { PML } & \text { progressive multifocal leukoencephalopathy } \\ \text { SAE } & \text { serious adverse event } \\ \text { TNF } \boldsymbol{} & \text { tumour necrosis factor alpha } \\ \text { UC } & \text { ulcerative colitis } \\ \text { VGSD } & \text { Vedolizumab Global Safety Database }\end{array}$




\begin{abstract}
Background and Aims:

Vedolizumab is a gut-selective antibody to $\alpha_{4} \beta_{7}$ integrin approved to treat moderate-to-severe ulcerative colitis and Crohn's disease in adults. Clinical trial data on patients meeting protocol-specified criteria may not reflect real-world clinical practice. This is a descriptive analysis of 4 years of post-marketing safety data on vedolizumab.
\end{abstract}

\title{
Methods:
}

The Vedolizumab Global Safety Database contains all adverse event reports collated by Takeda Pharmaceutical Company Ltd since vedolizumab approval [20-May-2014]. Adverse event reports received between approval and 19-May-2018 were identified using Medical Dictionary for Regulatory Activities version 21.0 Preferred Terms. The frequencies of the identified adverse events were calculated and categorized.

\section{Results:}

In approximately 208,050 patient-years of vedolizumab exposure, 32,752 patients reported 80,218 events: 37,662 and 34,259 events occurred in 14,191 patients with Crohn's disease and 14,042 patients with ulcerative colitis, respectively, while 8297 events occurred in 4519 individuals with other [off-label] or unreported indications. Overall, 5230 events [14\%] in patients with Crohn's disease and 3580 [10\%] in those with ulcerative colitis were serious. Most frequently reported were gastrointestinal events [Crohn's disease, $6156(16 \%)$ ulcerative colitis, 5701 (17\%)]. Patients with Crohn's disease and ulcerative colitis reported 251 malignancies $[<1 \%], 402$ hepatobiliary events $[<1 \%]$ and 5876 infections $[1137$ serious (19\%), 301 opportunistic (5\%)]. Patients aged $\geq 70$ years [2326 patients] reported $<10 \%$ of events. 


\section{Conclusions:}

Adverse event patterns were consistent with those from clinical trials, with no new safety concerns. Most reported events were non-serious and event frequency was low, considering patient-years of exposure. While limitations of post-marketing safety reports require acknowledgement, these real-world data support a favourable safety profile of vedolizumab.

Key Words: Clinical trials 


\section{Introduction}

Treatments for inflammatory bowel disease [IBD] are intended to reduce gastrointestinal inflammation. For Crohn's disease [CD] and ulcerative colitis [UC], this historically began with 5-aminosalicylate compounds, followed by corticosteroid therapy and then an oral immunomodulator, before an anti-tumour necrosis factor alpha [TNF $\alpha$ agent. However, there are safety concerns surrounding the use of immunomodulators, such as an increased risk of malignancy, including lymphoma, ${ }^{1}$ melanoma or non-melanoma skin cancer, ${ }^{2}$ as well as an increased risk of opportunistic infections. ${ }^{3}$

Vedolizumab is a humanized monoclonal antibody targeting $\alpha_{4} \beta_{7}$ integrin that is approved for the treatment of moderately to severely active CD and UC in adults. ${ }^{4,5}$ Many patients receiving vedolizumab will have already received an anti-TNF $\alpha$ therapy that has failed. A previous analysis of post-marketing data comparing patients with either prior or no prior exposure to anti-TNF $\alpha$ agents found that patients naïve to anti-TNF $\alpha$ agents reported significantly fewer adverse events [AEs; 94 vs 275 per 100 patient-years] and serious AEs [SAEs; 10 vs 18 per 100 patient-years] than patients who had previously been exposed. ${ }^{6}$

The efficacy and safety of vedolizumab has been investigated in three pivotal, phase 3 , randomized, placebo-controlled trials in patients with CD [GEMINI 2 and GEMINI 3] $]^{7,8}$ or UC [GEMINI 1], ${ }^{9}$ and safety data from these trials, along with three others (the GEMINI Long-Term Safety study and two phase 2 studies), have been previously combined and reported. ${ }^{10,11}$ The integrated safety summary of 2830 patients treated with vedolizumab for up to 5 years demonstrated that vedolizumab has a favourable safety profile. A recent systematic review evaluated data from the same six registration trials (including the aforementioned GEMINI studies) as well as six cohort studies reporting post-marketing data on 1049 patients 
covering 403 patient-years. ${ }^{11}$ It was found that vedolizumab therapy was not associated with an increase in side effects in the post-marketing setting compared with results seen during placebo-controlled registration trials. ${ }^{11}$ Most data analysed were from clinical trials that enrolled patients meeting stringent protocol-specified eligibility criteria, and the follow-up periods and numbers of patients were insufficient to allow full evaluation of the long-term safety of vedolizumab in real-world clinical practice. Thus, additional real-world evidence is needed to understand the effectiveness and safety profile of vedolizumab beyond that assessed in clinical trials. ${ }^{12,13}$ The aim of this descriptive analysis was to provide an update on the long-term, real-world safety profile of vedolizumab ${ }^{10,14-20}$ using 4 years of safety data captured in the Vedolizumab Global Safety Database [VGSD] since first marketing approval. 


\section{Materials and Methods}

\subsection{Data sources}

All post-marketing AE reports received by the licence holder, Takeda Pharmaceutical Company Ltd, since the date of first approval of vedolizumab on 20-May-2014, are held in the VGSD. The sources of these reports include spontaneous reports from patients, healthcare professionals and regulatory authorities, solicited reports from patient support and market research programmes, and reports extracted from the literature [Supplementary Table 1]. Data from reported events that may not be considered by patients and prescribers as AEs, such as 'pregnancy' and 'lactation', are required to be included in the VGSD by regulatory authorities. Reports of all non-serious AEs and SAEs from all post-marketing sources received between the date of approval and the data cut-off point were extracted from the VGSD and used for this analysis, 19-May-2018, were identified using Medical Dictionary for Regulatory Activities version 21.0 Preferred Terms and the frequencies of the identified adverse events were calculated and categorized. The estimated global vedolizumab exposure in the post-marketing setting was calculated based on the number of vials shipped worldwide, with accordance with maintenance dosing in the vedolizumab label, and to avoid overestimation of post-marketing exposure, 8 -week dosing intervals were assumed. Exposure-adjusted incidence rates were not calculated, as individual patient-level data are not available to the license holder in this post-marketing setting.

The collation and analysis of these post-marketing data did not involve any patient investigations that necessitated ethical approval at the national or institutional level. 


\subsection{Categorization of adverse events of clinical interest and additional factors}

Categories of $\mathrm{AE}$ that were of particular clinical interest in patients receiving vedolizumab were identified. The searches used are listed in Supplementary Text 1. Categories of interest included gastrointestinal AEs, hepatobiliary AEs, malignancies, infections, lupus-related AEs, infusion site reactions and AEs occurring in pregnancy, including congenital abnormalities. These categories were deemed to be of particular clinical interest either due to their associations with underlying patient disease or monoclonal antibody therapy, or for their value in assessing the impact of vedolizumab in populations that are not routinely included in clinical trials, such as pregnant patients.

Data on each AE category were examined further with respect to age [using $\geq 70$ years and $<70$ years as age cut-offs], as well as prior or concomitant therapy with other immunomodulators. In addition, the safety profile of vedolizumab in patients receiving concomitant anti-TNF $\alpha$ therapy was evaluated; although this is not a recommendation in the vedolizumab label, ${ }^{4,5}$ it is evident from AE reports that some patients in the post-marketing setting were receiving both therapies simultaneously. 


\section{Results}

\subsection{Patient characteristics}

In the context of an estimated 208,050 patient-years of vedolizumab exposure in the post-marketing setting, there were 80,218 AEs reported in 32,752 patients treated with vedolizumab [14,191 patients with CD, 14,042 patients with UC and 4519 patients with unspecified IBD, other [off-label] or unreported indications]. Of the 80,218 AEs reported, 37,662 [47\%] occurred in patients with CD, 34,259 [43\%] in those with UC, 815 [1\%] in individuals with unspecified IBD, $876[1 \%]$ in patients receiving therapy for off-label indications and 6606 [8\%] occurred in cases with no indication reported. Of the combined AE reports from patients with CD and UC, $59 \%$ of AEs reports were in women and $39 \%$ were in men; the remainder of AE reports did not specify sex [Table 1]. The focus of this manuscript is on patients with CD or UC; further data are provided for patients with other indications in the associated appendices.

When comparing reports from only patients with $\mathrm{CD}$ or UC, little difference was seen in the numbers of AE reports for each age group [Table 1], with most AEs reported in patients aged $<70$ years. In patients aged $<70$ years with CD, 31,439 AEs [ $83 \%$ of AEs reported in CD] were reported in 11,345 patients [ $80 \%$ of patients with $\mathrm{CD}$ ]; in patients aged $<70$ years with $\mathrm{UC}, 28,973 \mathrm{AEs}$ [ $85 \%$ of $\mathrm{AE}$ reports in $\mathrm{UC}]$ were reported in 11,580 patients [ $82 \%$ of patients with UC]. Patients aged $\geq 70$ years accounted for $8 \%$ of AEs reported in patients with CD [2934 AEs reported in 1065 patients (8\% of patients with CD)] and 9\% in UC [3050 AEs reported in 1153 patients ( $8 \%$ of patients with UC)].

Patients previously treated with anti-TNF $\alpha$ therapy accounted for $56 \%$ of AE reports in those with $\mathrm{CD}$ and $52 \%$ of $\mathrm{AE}$ reports in those with UC. Concomitant immunosuppressant use 
[excluding anti-TNF $\alpha$ therapy] was recorded in $17 \%$ of AE reports in patients with CD and $19 \%$ of those in patients with UC. In addition, $2 \%$ of AEs in patients with CD and $4 \%$ in patients with UC were experienced by individuals receiving anti-TNF $\alpha$ therapy concomitantly with vedolizumab [Table 1]. ${ }^{21}$ Concomitant corticosteroid therapy was recorded in $31 \%$ and $45 \%$ of $\mathrm{AE}$ reports in patients with $\mathrm{CD}$ or $\mathrm{UC}$, respectively, while no concomitant medication at all was recorded in $28 \%$ and $19 \%$ of respective AE reports.

Most AEs [79\%] were reported in individuals in post-marketing studies, including patient support programs [Supplementary Table 1]. A total of $62 \%$ of all AEs originated from patients in Canada, where most patients receive vedolizumab within a patient support programme, which generates a large volume of AEs; patients from the USA contributed the second largest percentage of AEs, at $21 \%$ of the total. The estimated exposure for Canada was 13,341 patient-years [ $6 \%$ of global exposure], while the estimated exposure for the USA was 105,907 patient-years [51\% of global exposure; country with greatest global exposure]. The country with the second highest number of patient-years of exposure to vedolizumab was Germany, with a total of 23,342 patient-years [11\% of global exposure].

\subsection{SAEs and non-serious AEs}

Of the 80,218 reported AEs, 10,329 [13\%; 5230 events in patients with CD, 3580 in patients with UC] were serious. Exacerbation of underlying disease, hospitalization and death were among the five most frequently reported SAEs in patients with CD and UC [Figure 1]. Death refers to reports in which the reported AE term was 'death'; most AE reports of 'death' arose from insurance databases and patient support programme data and were notifications that the patient had died whilst receiving vedolizumab, with no additional information provided. The other most frequent SAEs were intestinal obstruction [3\%], and surgery [2\%] in CD, and 
colectomy [3\%], Clostridium difficile infection/colitis [2\%], abdominal pain and pneumonia [1\% each] in UC [Figure 1].

The remaining 69,889 AEs reported were non-serious [87\%; 32,432 events in patients with $\mathrm{CD}$ and 30,679 in patients with $\mathrm{UC}$. For patients with $\mathrm{CD}$ or $\mathrm{UC}$, exacerbation of underlying disease and transient increases in blood pressure were among the five most frequently reported non-serious AEs, along with ineffectiveness of vedolizumab [Figure 1]. The remaining most frequently reported non-serious $\mathrm{AE}$ terms included fatigue [3\%] in both $\mathrm{CD}$ and $\mathrm{UC}$, and arthralgia $[2 \%]$ in $\mathrm{CD}$ and headache $[2 \%]$ in UC.

\subsection{Gastrointestinal AEs}

Gastrointestinal [GI] AEs were the most frequently reported events and accounted for $15 \%$ of all AEs, with 11,857 reported in patients with CD or UC [6156 (16\% of AEs in CD) and 5701 (17\% of AEs in UC), respectively]. The four most frequently reported GI AEs were the same in both indications [Figure 2]: exacerbation of underlying disease [ $22 \%$ and $28 \%$ of AEs in patients with $\mathrm{CD}$ and $\mathrm{UC}$, respectively], diarrhoea [10\% and $9 \%$, respectively], abdominal pain $[10 \%$ and $8 \%$, respectively] and nausea [ $9 \%$ and $7 \%$, respectively]. The fifth most frequent GI AE was vomiting in patients with $\mathrm{CD}$ [5\% of events] and haematochezia in those with UC [6\% of events].

\subsection{Malignancies}

In total, 299 malignancy AE reports were received, of which 126 [42\%] contained no data on either the diagnosis date of the malignancy relative to vedolizumab therapy initiation, or the start date of vedolizumab therapy. Overall, 251 malignancies were reported in patients with CD or UC [134 and 117, respectively], representing less than 1\% of all AEs. A total of 128 malignancies $[43 \%]$ were reported to have occurred within 1 year of the start of vedolizumab 
treatment, while 45 malignancies were reported to have occurred at least 1 year after the start of treatment. Lower GI tract malignancies were the most frequently reported in patients with CD [21 events], followed by renal and bladder [18 events] and skin [unspecified and other; 12 events]. Lower GI tract malignancies were also the most frequently reported in patients with UC [34 events], followed by lymphoma [14 events] and respiratory malignancies [11 events; Figure 2]. Detailed malignancy data have been published separately. ${ }^{22}$

\subsection{Hepatobiliary AEs}

In total, 402 hepatobiliary AEs were reported in patients with CD or UC [186 and 216, respectively], and accounted for less than $1 \%$ of all AEs reported. The five most frequently reported hepatobiliary AEs were similar for CD and UC [Figure 2] and were generally related to changes in hepatic enzyme levels; the two most frequently reported were increased hepatic enzymes [20\% and $22 \%$ of events, respectively] and increased alanine aminotransferase [ $8 \%$ and $7 \%$, respectively].

\subsection{Infusion site reactions}

In total, 499 infusion site reactions were reported in patients with CD or UC [264 and 235, respectively; Figure 2], accounting for less than 1\% of all AEs reported. The most frequent infusion site reactions reported in patients with $\mathrm{CD}$ and $\mathrm{UC}$ were infusion site extravasation [27\% of all infusion site reactions reported for $\mathrm{CD}, 26 \%$ for $\mathrm{UC}]$, infusion site pain $[22 \% \mathrm{CD}$, $21 \% \mathrm{UC}]$ and infusion site bruising $[13 \% \mathrm{CD}, 11 \% \mathrm{UC}]$. When comparing only patients with $\mathrm{CD}$ or $\mathrm{UC}$, the majority of infusion site reaction reports came from patients aged $<70$ years [239 reports (91\%) in CD and 210 reports (89\%) in UC]. The majority of infusion site reactions in patients with CD or UC [291 AEs (58\%)] were reported by patients who had previously been exposed to anti-TNF $\alpha$ therapy. A total of 325 infusion site reactions [65\%] were reported in patients receiving no concomitant immunosuppressive therapy, while 104 
[21\%] and 70 [14\%] were reported in patients receiving concomitant immunosuppressives and patients with no concomitant medication at all, respectively.

\subsection{Lupus erythematosus and associated conditions}

There were ten lupus-related AEs in patients with $\mathrm{CD}$ [seven in patients aged $<70$ years, three in patients with unreported age] and nine in patients with $\mathrm{UC}$ [eight in patients aged $<70$ years and one occurring in a patient with unreported age], representing less than $1 \%$ of all reported AEs. Of these, seven AE reports were lupus-like syndrome and three were systemic lupus erythematosus in $\mathrm{CD}$, and six and three reports, respectively, in patients with UC [Figure 2]. Ten of the 19 reports detailed previous anti-TNF $\alpha$ therapy [six CD, four UC], four reported no prior exposure to anti-TNF $\alpha$ therapy [one $\mathrm{CD}$, three $\mathrm{UC}$ ] and five recorded no prior medications at all [three $\mathrm{CD}$, two $\mathrm{UC}]$. All lupus-related $\mathrm{AE}$ reports in patients with $\mathrm{CD}$ detailed receiving either no concomitant immunosuppressive therapy or no concomitant medication at all. In patients with UC, two lupus-related AEs were in patients receiving concomitant immunosuppressives, six AEs were in patients not receiving concomitant immunosuppressive therapy and one $\mathrm{AE}$ was in a patient receiving no concomitant medication at all. Of the total 25 lupus-related AEs reported across all indications, 18 (72\%) occurred in female patients whilst the remaining seven AEs $(28 \%)$ were in male patients. Data regarding antinuclear and anti-DNA antibodies are provided in Supplementary Table 3.

\subsection{Overall infections}

A total of 5876 infections were reported [3064 and 2812 in patients with CD and with UC, respectively], representing $7 \%$ of all AEs across every indication. Generally, the most frequently reported infections were similar in patients with $\mathrm{CD}$ and $\mathrm{UC}$; the three most frequent infection AEs were nasopharyngitis [16\% of infection AEs reported in CD, 22\% in 
$\mathrm{UC}]$, influenza [ $8 \%$ of infection AEs reported in $\mathrm{CD}$ and in $\mathrm{UC}]$ and sinusitis $[5 \%$ in $\mathrm{CD}$ and $7 \%$ in UC]. Other infections reported in at least $2 \%$ of patients included pneumonia, bronchitis, urinary tract infection, C. difficile infection/colitis, unspecified infection, herpes zoster [opportunistic], lower respiratory tract infection and ear infection. A total of 608 gastrointestinal infections were recorded in patients with $\mathrm{CD}$ or $\mathrm{UC}$ [305 infections in $\mathrm{CD}$, 303 in UC], accounting for $10 \%$ of total infections in patients with these indications.

\subsubsection{Serious infections}

Of the infections reported, 1137 were serious: 710 in patients with CD and 427 in patients with UC. These represented over $1 \%$ of the total number of AEs. The five most frequently reported serious infections were similar across the two indications [Figure 3]. Pneumonia was the most frequent serious infection in patients with $\mathrm{CD}[10 \%$ of serious infection events for this indication] and the second most frequent in patients with UC [10\% of serious infection events for UC]. C. difficile infection/colitis was the most frequent serious infection in patients with UC [15\% of serious infection events for this indication]. Sepsis and unspecified infection were among the five most frequently reported serious infections in both indications [Figure 3].

\subsubsection{Opportunistic infections}

Opportunistic infections may be defined as infections caused by microorganisms that are normally non-pathogenic, but are able to cause serious disease when the immune system is impaired as a result of another unrelated disease or its treatment. ${ }^{23,24}$ When considering only opportunistic infections, 301 AEs were reported in patients with CD or UC [100 and 201, respectively; Figure 3], accounting for less than 1\% of all AEs. The most frequently reported opportunistic infections were similar in the two indications [Figure 3] and included $C$. 
difficile infection/colitis [ $72 \%$ of opportunistic infection $\mathrm{AE}$ reports in patients with $\mathrm{CD}, 80 \%$ of opportunistic infection reports in UC] and cytomegalovirus infection/colitis [ $8 \%$ and $12 \%$ of opportunistic infection $\mathrm{AE}$ reports in patients with $\mathrm{CD}$ and $\mathrm{UC}$, respectively]. One case of progressive multifocal leukoencephalopathy $[\mathrm{PML}]$ was reported in a human immunodeficiency virus [HIV]-positive patient with CD who had been on long-term immunosuppressant therapy. An independent adjudication committee of experts with experience in PML and HIV concluded that the most probable cause of PML was the patient's HIV status together with their prolonged immunosuppressant medication use.

Five tuberculosis events were reported in patients with $\mathrm{CD}$, including one report each of cutaneous, latent and gastrointestinal tuberculosis, as well as two cases where infection location was unspecified; four events were reported in patients with UC, including two AE reports of latent tuberculosis and two AE reports of tuberculosis with unspecified infection location [Figure 3]. Four of the five tuberculosis AEs recorded in patients with CD originated from patients aged $<70$ years, while the final AE had no associated age data reported. In patients with UC, two AEs were reported in patients aged $<70$ years, one in a patient aged $\geq 70$ years and the other had no associated age data. Of the five tuberculosis infections recorded in patients with $\mathrm{CD}$, one was reported in a patient with previous exposure to antiTNF $\alpha$ therapy, while the remaining four events occurred in patients without any prior medications reported. Similarly, in patients with UC, one event of tuberculosis each was recorded in patients previously exposed and naïve to anti-TNF $\alpha$ therapy, respectively, while two tuberculosis infections were documented in patients with no prior medications reported at all. 
There were nine AEs of histoplasmosis infection in patients with CD and none in patients with UC [Figure 3]. Of these infections, seven occurred in patients aged $<70$ years and the remainder had no associated age data. A total of five events were reported in patients previously exposed to anti-TNF $\alpha$ therapy, with the final four infections occurring in patients without any prior medications reported. There were three histoplasmosis infections each reported in patients with and without concomitant immunosuppressive therapy, while the remaining three events were in patients without any reported concomitant medications at all. There were two AEs of nocardiosis reported in patients with $\mathrm{CD}$ and none in patients with UC [Figure 3]; one was in a patient aged $<70$ years who was naïve to anti-TNF $\alpha$ therapy and the other was in a patient aged $\geq 70$ years with prior exposure to anti-TNF $\alpha$ therapy.

\subsection{Adverse events in populations of particular clinical interest}

\subsubsection{Patients aged $\geq 70$ years}

In the 2218 patients aged $\geq 70$ years with CD or UC, there were 5984 AEs [2934 in CD and 3050 in UC], equal to 7\% of all AEs [Table 1]. Of these reported AEs, 449 [15\%; CD] and $481[16 \% ; \mathrm{UC}]$, respectively, were serious. The most frequently reported AEs in this age group were GI AEs $[16 \%$ of AEs in patients aged $\geq 70$ with $\mathrm{CD}, 17 \%$ in $\mathrm{UC}]$, followed by infections [8\% of AEs in both patients with $\mathrm{CD}$ and those with $\mathrm{UC}$; Table 2]. For comparison, in patients aged $<70$ years with $\mathrm{CD}$ or UC, 60,412 AEs were reported [31,439 in CD and 28,973 in UC; Table 1], and, similarly, GI AEs and infections were the most frequently reported AEs [Table 2].

\subsubsection{Patients with prior exposure to anti-TNF $\alpha$ agents}

In total, $56 \%$ [21,145 AEs] and 52\% [17,749 AEs] of AEs reported in patients with CD and UC, respectively, detailed prior use of anti-TNF $\alpha$ therapy and 16\% [5986 AEs] and 25\% 
[8627 AEs] recorded no prior anti-TNF $\alpha$ therapy, while AE reports containing no information on prior medication accounted for 28\% [10,531 AEs] and 23\% [7883 AEs] of AEs, respectively [Table 1]. In total, GI AEs accounted for $17 \%$ of AEs in both patients with $\mathrm{CD}$ and $\mathrm{UC}$ reporting prior anti-TNF $\alpha$ therapy exposure [3571 AEs in CD, $3019 \mathrm{UC}$ ], respectively, as well as $17 \%$ of AEs in patients without prior exposure to anti-TNF $\alpha$ therapy for both indications [1029 AEs in CD, $1441 \mathrm{UC}$; Table 2]. In patients with CD or UC who had prior exposure to anti-TNF $\alpha$ therapy, infections, serious infections and opportunistic infections represented 9\% [3343 AEs], 1\% [576 AEs] and <1\% [157 AEs] of combined AE reports for these patients, respectively, while malignancies accounted for $<1 \%$ [116 AEs] in this group. In patients with CD or UC without prior exposure to anti-TNF $\alpha$ therapy, $8 \%$ [1204 AEs], 1\% [183 AEs] and $<1 \%$ [56 AEs] of combined AE reports for this patient group pertained to infections, serious infections and opportunistic infections, respectively, with malignancies accounting for $<1 \%$ [41 AEs] of AEs reported.

\subsubsection{Patients receiving vedolizumab with and without concomitant biologics}

Of the total 80,218 AEs reported in a total of 32,752 patients, 2847 events [4\% of all AEs; 1285 in patients with $\mathrm{CD}, 1363$ in patients with $\mathrm{UC}$ ] were in 1112 patients receiving vedolizumab with concomitant biologics [ $3 \%$ of all patients; 460 patients with $\mathrm{CD}, 543$ patients with UC]. A total of 54,855 AEs [68\% of all AEs; including 25,929 AEs in patients with CD and 26,272 with UC] were reported in 20,201 patients [ $62 \%$ of all patients; 8861 patients with $\mathrm{CD}$ and 10,113 with $\mathrm{UC}$ ] receiving concomitant medication which did not include other biologics. For this patient group, 4785 patients [all indications; 24\%] received concomitant immunosuppressants, while 9892 patients [all indications; 49\%] received concomitant corticosteroids. 
The distribution of categories of AE by indication was similar in patients receiving vedolizumab with concomitant biologic therapy and those receiving concomitant medications that did not include other biologics. In patients receiving concomitant biologic therapy, 202 infections [7\% of AEs reported in this patient group] were reported in 1003 patients with CD or UC, $43[21 \%]$ of which were serious. There were seven post-operative complications $[<1 \%], 16$ infusion site reactions $[<1 \%]$ and two malignancies $[<1 \%]$ reported in patients with CD or UC, while seven AEs resulting in a fatal outcome were reported in five patients $[<1 \%$; four $\mathrm{CD}$, one $\mathrm{UC}]$. In patients not receiving concomitant biologic therapy, there were 4414 infections [8\% of AEs reported for this patient group] reported in 18,974 patients with CD or UC, of which 804 [18\%] were serious, along with 186 post-operative complications $[<1 \%], 453$ infusion site reactions $[<1 \%], 176$ malignancies $[<1 \%]$ and 140 fatal AEs $[<1 \%$; $80 \mathrm{CD}, 60 \mathrm{UC}]^{21}$

\subsubsection{Pregnancy}

In total, there were 651 pregnancy reports in patients with $\mathrm{CD}$ or UC [353 in patients with CD and 298 in patients with UC]. These reports included AEs reported by both pregnant women receiving vedolizumab and the pregnant partners of male patients receiving vedolizumab. Of the 651 reports, 46\% included an AE term [302 reports; Table 3 details AE terms]; the remaining reports contained no AEs and only reported the occurrence of a pregnancy [recorded for regulatory purposes]. The most frequently reported AEs in patients with CD were spontaneous abortion and exacerbation of CD [29 and 23 events, respectively (3\% each)] and in patients with UC were exacerbation of UC and spontaneous abortion [23 and 19 , respectively ( $3 \%$ each); Table 3]. Where details were provided, most spontaneous abortions occurred during the first trimester and causality was confounded by maternal medical history and concomitant medication use. There were an additional 56 pregnancy 
reports in patients with unspecified IBD, and 7 and 250 pregnancy reports in patients with an off-label or unreported indication, respectively. Data on spontaneous abortions and obstetric histories can be seen in Supplementary Text 3.

\subsubsection{Congenital abnormalities}

There were 12 reports of congenital abnormalities in 10 different children; one child had three congenital abnormalities reported, while one abnormality was reported in each of the remaining nine children. Of these, six reports were in six children of patients with CD or UC for which there was insufficient information provided to allow assessment of causality in relation to vedolizumab treatment. The abnormalities reported in these six reports were transposition of the great vessels, pyloric stenosis, pulmonary valve stenosis, congenital heart disease, Kabuki syndrome and development hip dysplasia.

Associated confounding factors impacted the ability to discern causality in three further reports of congenital abnormalities. There was one report of gastroschisis [confounded by smoking], one report of congenital megacolon [confounded by smoking and concomitant prednisolone] and one report of pulmonary malformation. Finally, there was one further pregnancy that had three congenital abnormalities reported (penile torsion, congenital urethral anomaly and strabismus) for which a causal association with vedolizumab could not be excluded based on the information provided.

\subsection{AE outcomes and vedolizumab continuation}

At the time of reporting, $48 \%$ of all AEs [for which continuation data were available] were resolved, resolving or resolved with sequelae [60\% of serious and $44 \%$ of non-serious AEs]. A summary of outcome data for individual types of AE in patients with $\mathrm{CD}$ or UC are 
presented in Figure 4. Vedolizumab treatment was continued by $81 \%$ of patients with CD or UC who had experienced an AE [for whom continuation data were available]. A summary of continuation data for each category of $\mathrm{AE}$ in patients with $\mathrm{CD}$ or $\mathrm{UC}$ is presented in Figure 5.

\subsection{Vedolizumab use in other indications}

Detail on types of AEs reported in patients receiving vedolizumab for unspecified IBD or for an off-label or unreported indication are presented in Supplementary Tables 4-8. 


\section{Discussion}

This analysis describes 4 years of post-marketing safety data captured in the VGSD to provide further evidence on the safety profile of vedolizumab in real-world clinical practice. In over 200,000 patient-years of vedolizumab exposure, $87 \%$ of reported AEs were nonserious, with most related to the patients' IBD or constitutional events. As $81 \%$ of patients [for whom data were available] who experienced an AE continued therapy, it suggests that these AEs were unlikely to be directly related to vedolizumab and/or the benefits of treatment outweighed the impact of these AEs on patients. This also implies considerable treatment persistence with vedolizumab.

The most frequently reported non-serious AEs included events related to the underlying disease and ineffectiveness, and labelled events [such as fatigue, arthralgia, headache and nausea]. ${ }^{4,5}$ The most frequently reported SAEs included those directly related to the underlying disease, $C$. difficile infection/colitis and pneumonia. Although these events were most frequently reported, numbers were low with only exacerbation of underlying disease reported as over $4 \%$ of all reported events [Figure 1]. Frequencies of events of particular clinical interest were also low: infusion-related reactions $[<1 \%$ of all $\mathrm{AEs}$ in $\mathrm{CD}$ and UC patients]; lupus type AEs $[<1 \%, \mathrm{n}=19]$; hepatobiliary AEs $[<1 \%]$ and malignancies $[<1 \%]$. Given the extent of exposure, these data support the contention that vedolizumab is rarely associated with these events.

Overall, GI events were the most frequently reported (15\% of all AEs), with a rate of 5.7 events per 100 patient-years in patients with CD or UC [ 4.3 events per 100 patient-years excluding exacerbations of $\mathrm{CD}$ or $\mathrm{UC}$ ]; which is substantially lower than in vedolizumab clinical trials [59.8 and 114.5 events per 100 patient-years in patients receiving vedolizumab 
or placebo, respectively]. ${ }^{10}$ The incidence rate of GI events in placebo-treated patients in the clinical trials suggest that many of the frequently reported post-marketing GI events may be attributable to underlying disease, although this comparison must be interpreted cautiously considering the limitations of post-marketing reports.

The increased risk of lower GI tract/colorectal cancers in patients with IBD are well documented, as are the risks associated with IBD treatments (anti-TNF $\alpha$ agents and thiopurines). ${ }^{1,2,25-27}$ Concerning characterisation, lower GI tract malignancies were the most frequently reported, while no correlation with site or indication was seen with non-GI malignancies. A total of $39 \%$ of malignancies occurred in patients with CD or UC who received prior and/or concomitant anti-TNF $\alpha$ therapy. Reference populations of patients with IBD for comparison with post-marketing data are challenging to identify; however, incidence of malignancy appears lower in patients receiving vedolizumab in the post-marketing setting than would be expected based on analysis of the Optum's Clinformatics Data Mart database. ${ }^{22}$ Patients with IBD are also known to have an increased risk of hepatobiliary disorders due to immunological abnormalities, sclerosing cholangitis, fatty liver, gall bladder disease and toxicities of commonly used treatments for IBD. Most reported hepatobiliary disorders were associated with changes in hepatic enzyme levels.

In vedolizumab clinical trials, there was no overall increase in the risk of infection for patients treated with vedolizumab versus placebo, and the incidences of most individual infections were similar between both groups. ${ }^{10}$ In this study, $7 \%$ of all reported AEs were infections, with the most frequently reported infections in patients with CD and UC being labelled events: nasopharyngitis, influenza and sinusitis. ${ }^{4,5}$ In patients with $\mathrm{CD}$, the most frequently reported serious infection was pneumonia, followed by abscess, compared with $C$. 
difficile infection/colitis, followed by pneumonia in patients with UC. Opportunistic infections in patients with CD or UC accounted for less than $1 \%$ of all AEs, with the most frequently reported in both indications being $C$. difficile infection/colitis and cytomegalovirus infection/colitis. For the single event of PML, the most probable cause was the patient's HIV status together with his prolonged use of immunosuppressants.

Concomitant use of immunosuppressive therapy [not recommended with vedolizumab ${ }^{4,5}$ ] was recorded in $18 \%$ of $\mathrm{AE}$ reports from patients with $\mathrm{CD}$ or $\mathrm{UC}$, and concomitant corticosteroid therapy in $38 \%$ of AE reports for these indications. This is likely to have increased the susceptibility of these patients to infections. ${ }^{28,29}$ Patients receiving concomitant corticosteroids and vedolizumab reported higher percentages of infections and serious infections than patients without concomitant corticosteroid use, as well as a markedly higher percentage of opportunistic infections, although there was no increase in serious opportunistic infections such as candidiasis, disseminated herpes zoster or cytomegalovirus. Based on these results, concomitant use of corticosteroids may increase the likelihood of patients experiencing infection AEs. Further analyses of vedolizumab-associated infections from the Long-Term Safety study will be reported separately, while post-marketing data have already been published. ${ }^{30-32}$

Considering populations of particular clinical interest, the most frequently reported events in patients with $\mathrm{CD}$ and $\mathrm{UC}$ aged $\geq 70$ years were similar to those seen in patients aged $<70$ years (GI and infection AEs). The findings in this study, suggest that the safety profile in those aged $\geq 70$ years is consistent with those aged $<70$ years; however, limitations of postmarketing reports should be considered when interpreting this data. Patients reporting prior anti-TNF $\alpha$ therapy exposure or concomitant biologics are also of interest. While the 
vedolizumab label advises concomitant use with anti-TNF $\alpha$ therapy be avoided, it also states that population pharmacokinetic analysis has shown prior treatment with anti-TNF $\alpha$ therapy and co-administered immunomodulators does not have a clinically meaningful effect on vedolizumab pharmacokinetics. ${ }^{4}$ Real-world safety data in these patients is required, as they were under-represented in the registrational clinical trials for vedolizumab. Here the vedolizumab safety profile was similar in patients with and without prior anti-TNF $\alpha$ therapy exposure. The most frequently reported AEs in both patient groups, and in both CD and UC, were infections and GI AEs, as expected for patients with IBD receiving immunosuppressants. In patients receiving concomitant biologics and vedolizumab, a higher number of AEs was expected owing to the receipt of systemic immunosuppressants.

However, owing to the small number of patients, and lack of data regarding treatment timing, we cannot conclude whether concomitant biologic and vedolizumab use increases the risk of AEs.

There were 651 post-marketing reports of pregnancy, $46 \%$ of which had an associated AE, with the most frequently reported being spontaneous abortion $[3 \%$ in both $\mathrm{CD}$ and UC; 48 AEs]. Most cases of spontaneous abortion were confounded [Supplementary Text 3]. During pregnancy, therapeutic monoclonal antibodies move across the placenta in a linear fashion, increasing as pregnancy progresses and peaking in the third trimester. ${ }^{4,5}$ Most spontaneous abortions in this study occurred in the first trimester. These results must be considered with respect to the limitations of the data available; detailed clinical data were not provided and spontaneous abortions could be attributable to numerous causes. A low number of congenital abnormalities were reported, but insufficient data were available to meaningfully assess causality to vedolizumab. In vedolizumab preclinical studies, no concerns with fertility or fetal harm were identified, ${ }^{4,5}$ nevertheless, vedolizumab should only be used during 
pregnancy or in male patients with pregnant partners if the benefits to the patient outweigh potential risks to the unborn child., ${ }^{4,5}$

The strengths of this study include the extensive patient-years of exposure, the large total number of patients and the data reported across an international setting. Limitations of postmarketing data from the VGSD should be considered when interpreting these findings, which include the reporting of incomplete data [e.g. dosing regimens used], voluntary reporting of AEs [which may result in many AEs going unreported], increased reporting of SAEs, lack of access to individual patient-level data and difficulty in establishing a causal relationship between vedolizumab and the AE of interest. Data were also limited regarding extraintestinal manifestations of IBD, due to this inability to access patient-level information.

In the context of 208,050 patient-years of vedolizumab exposure in 32,752 patients, for most reported AEs the numbers were low. No new safety signals have been identified from this study, including in the sub-populations of patients aged $\geq 70$ years and those with prior or concomitant exposure to anti-TNF $\alpha$ therapy. The post-marketing safety profile is consistent with that observed during clinical trials. Further safety data continue to be collected through the Organization of Teratology Information Services Pregnancy Registry [NCT02678052], the post-authorization safety study and routine post-marketing pharmacovigilance. Data from the GEMINI Long-Term Safety study [NCT00790933] will be reported separately. 


\section{Funding}

This work was supported by Takeda Pharmaceutical Company Ltd.

\section{Acknowledgements}

Medical writing assistance was provided by Alex Kisbey and Fraser Harris of Oxford PharmaGenesis, Oxford, UK.

\section{Conflicts of Interest}

R.C. has received speakers' bureau honoraria from AbbVie and Takeda. He has served as a consultant, adviser or member of scientific advisory boards for AbbVie, Celgene, Eli Lilly, Hospira, Janssen, Pfizer, Sandoz, Takeda and UCB. He has received grants or research support from AstraZeneca, Celgene, Gilead, Medimmune, Mesoblast Ltd, Osiris Therapeutics, Pfizer, Receptos, RedHill Biopharma, Sanofi and UCB.

F.B. and A.B. are employees of Takeda Pharmaceuticals International Co.

S.T. is employed by Oxford University Hospitals NHS Foundation Trust and the University of Oxford, UK. He has received grants or research support from AbbVie, Buhlmann, IOIBD, Lilly, MediAdd, UCB, Vifor and the Norman Collisson Foundation; consulting fees from AbbVie, Ajinomoto, Almirall, Amgen, Arena, Asahi, Atlantic, Bioclinica, Biogen, Boehringer Ingelheim, Bristol-Myers Squibb, Calcico, Celgene, Chemocentryx, Cosmo, Covance, Enterome, Falk, Ferring, Genentech, Gilead, Giuliani SpA, GlaxoSmithKline, Glenmark, Grünenthal, Immunocore, Immunometabolism, Istesso, Janssen, Lexicon, Lilly, Medarex, Merck, MSD, Napp, Neovacs, Novartis, Novo Nordisk, NPS Pharmaceuticals, Ocera, Otsuka, Pfizer, PharmOlam, Phillips, Proximagen, Quintiles, Receptos, Robarts, Roche, Sandoz, Shire, Sigmoid Pharma, Takeda, Theravance, TiGenix, Topivert, UCB, 
Vertex, VHsquared, Vifor, Warner Chillcott and Zeria; and speaker fees from AbbVie, Amgen, Biogen, Ferring, Sandoz, Shire, Takeda and Zeria. He has no stocks or share options.

\section{Author Contributions}

All authors have made substantial contributions to the conception and design of the study, acquisition, analysis and interpretation of data, revising the article critically for important intellectual content and providing final approval of the version to be submitted.

This manuscript, including related data, figures and tables, has not been previously published and is not under consideration elsewhere. 


\section{References}

1. Kotlyar DS, Lewis JD, Beaugerie L, et al. Risk of lymphoma in patients with inflammatory bowel disease treated with azathioprine and 6-mercaptopurine: a metaanalysis. Clin Gastroenterol Hepatol 2015;13:847-58 e4.

2. Long MD, Martin CF, Pipkin CA, et al. Risk of melanoma and nonmelanoma skin cancer among patients with inflammatory bowel disease. Gastroenterology 2012;143:390-9 e1.

3. Inflammatory Bowel Disease Group, Chinese Society of Gastroenterology, Chinese Medical Association. Evidence-based consensus on opportunistic infections in inflammatory bowel disease (republication). Intest Res 2018;16:178-93.

4. Food and Drug Administration. Enytvio. Prescribing Information. Accessed July 2018 at https://www.accessdata.fda.gov/drugsatfda_docs/label/2014/125476s000lbl.pdf.

5. European Medicines Agency. Entyvio. Summary of Product Characteristics. Accessed July 2018 at http://www.ema.europa.eu/docs/en_GB/document library/EPAR Product Information/human/002782/WC500168528.pdf.

6. Cohen R, Bhayat F, Hantsbarger G, et al. Safety of vedolizumab in patients naïve to treatment with TNF antagonists compared with patients with prior use of TNF antagonists. J Crohns Colitis 2018;12:S032-S4.

7. Sandborn WJ, Feagan BG, Rutgeerts $\mathrm{P}$, et al. Vedolizumab as induction and maintenance therapy for Crohn's disease. $N$ Engl J Med 2013;369:711-21.

8. Sands BE, Feagan BG, Rutgeerts P, et al. Effects of vedolizumab induction therapy for patients with Crohn's disease in whom tumor necrosis factor antagonist treatment failed. Gastroenterology 2014;147:618-27 e3.

9. Feagan BG, Rutgeerts P, Sands BE, et al. Vedolizumab as induction and maintenance therapy for ulcerative colitis. N Engl J Med 2013;369:699-710.

10. Colombel JF, Sands BE, Rutgeerts P, et al. The safety of vedolizumab for ulcerative colitis and Crohn's disease. Gut 2017;66:839-51.

11. Bye W, Jairath V, Travis S. Systematic review: the safety of vedolizumab for the treatment of inflammatory bowel disease. Aliment Pharmacol Ther 2017;46:3-15.

12. Sherman RE, Anderson SA, Dal Pan GJ, et al. Real-world evidence-what is it and what can it tell us. N Engl J Med 2016;375:2293-7.

13. Khosla S, White R, Medina J, et al. Real world evidence (RWE) - a disruptive innovation or the quiet evolution of medical evidence generation? F1000Res 2018;7.

14. Dave M, Purohit T, Razonable R, et al. Opportunistic infections due to inflammatory bowel disease therapy. Inflamm Bowel Dis 2014;20:196-212.

15. Ford AC, Peyrin-Biroulet L. Opportunistic infections with anti-tumor necrosis factoralpha therapy in inflammatory bowel disease: meta-analysis of randomized controlled trials. Am J Gastroenterol 2013;108:1268-76.

16. McLean LP, Cross RK. Adverse events in IBD: to stop or continue immune suppressant and biologic treatment. Expert Rev Gastroenterol Hepatol 2014;8:22340.

17. Magro F, Peyrin-Biroulet L, Sokol H, et al. Extra-intestinal malignancies in inflammatory bowel disease: results of the 3rd ECCO Pathogenesis Scientific Workshop (III). J Crohns Colitis 2014;8:31-44.

18. Nahon S, Cadranel JF, Chazouilleres O, et al. Liver and inflammatory bowel disease. Gastroenterol Clin Biol 2009;33:370-81. 
19. Sorensen PS, Bertolotto A, Edan G, et al. Risk stratification for progressive multifocal leukoencephalopathy in patients treated with natalizumab. Mult Scler 2012;18:14352.

20. Rogler G. Gastrointestinal and liver adverse effects of drugs used for treating IBD. Best Pract Res Clin Gastroenterol 2010;24:157-65.

21. Cohen R, Bhayat F, Blake A, et al. Post-marketing safety experience of vedolizumab in patients receiving concomitant treatment with other biologics. 14th Congress of the European Crohn's and Colitis Organisation 2019.

22. Card T, Ungaro R, Bhayat F, et al. Vedolizumab use is not associated with increased malignancy incidence: GEMINI Long-Term Safety study results and post-marketing data. 14th Congress of the European Crohn's and Colitis Organisation 2019.

23. Rahier JF, Magro F, Abreu C, et al. Second European evidence-based consensus on the prevention, diagnosis and management of opportunistic infections in inflammatory bowel disease. Journal of Crohn's and Colitis 2014;8:443-68.

24. Faria R, Pereira C, Alves R, et al. Chapter 15 - Opportunistic Infections and Autoimmune Diseases. In: Shoenfeld Y, Agmon-Levin N, Rose NR, editors. Infection and Autoimmunity (Second Edition) Amsterdam: Academic Press; 2015: 251-77.

25. Jess T, Gamborg, M., Matzen, P., Munkholm, P., Sorensen, T. I.,. Increased risk of intestinal cancer in Crohn's disease: a meta-analysis of population-based cohort studies. Am J Gastroenterol 2005;100:2724-9.

26. Jess T, Rungoe C, Peyrin-Biroulet L. Risk of colorectal cancer in patients with ulcerative colitis: a meta-analysis of population-based cohort studies. Clin Gastroenterol Hepatol 2012;10:639-45.

27. Lichtenstein GR, Rutgeerts P, Sandborn WJ, et al. A pooled analysis of infections, malignancy, and mortality in infliximab- and immunomodulator-treated adult patients with inflammatory bowel disease. Am J Gastroenterol 2012;107:1051-63.

28. Brassard P, Bitton A, Suissa A, et al. Oral corticosteroids and the risk of serious infections in patients with elderly-onset inflammatory bowel diseases. $\mathrm{Am} \mathrm{J}$ Gastroenterol 2014;109:1795-802.

29. Toruner M, Loftus EV, Jr., Harmsen WS, et al. Risk factors for opportunistic infections in patients with inflammatory bowel disease. Gastroenterology 2008;134:929-36.

30. Bhayat F, Blake A, Travis SP. Post-marketing experience of vedolizumab in inflammatory bowel disease: analysis of pneumonia and other respiratory tract infections. Lung 2017;2:2.

31. Feagan BG, Bhayat F, Khalid M, et al. Respiratory tract infections in patients with inflammatory bowel disease: safety analyses from vedolizumab clinical trials. $J$ Crohns Colitis 2018;12:905-19.

32. Ng SC, Hilmi IN, Blake A, et al. Low frequency of opportunistic infections in patients receiving vedolizumab in clinical trials and post-marketing setting. Inflamm Bowel Dis 2018;24:2431-41. 


\section{Figure Legends}

Figure 1. Most frequently reported serious and non-serious AEs reported in patients with Crohn's disease or ulcerative colitis in the post-marketing setting.

Figure 2. Five most frequently reported AEs in patients with Crohn's disease or ulcerative colitis in the post-marketing setting. ${ }^{\text {a }}$

Figure 3. Most frequently reported infections reported in patients with Crohn's disease or ulcerative colitis in the post-marketing setting.

Figure 4. Outcomes of adverse events reported in the post-marketing setting in patients with Crohn's disease and ulcerative colitis.

Figure 5. Impact of the adverse events reported in the post-marketing setting on vedolizumab treatment continuation in patients with Crohn's disease and ulcerative colitis. 
Table 1. Baseline characteristics of patients with Crohn's disease or ulcerative colitis in whom an adverse event was reported in the post-marketing setting.

\begin{tabular}{|c|c|c|c|c|}
\hline \multirow[b]{2}{*}{ Characteristic } & \multicolumn{2}{|c|}{ Number of events reported } & \multicolumn{2}{|c|}{$\begin{array}{c}\text { Number of patients reporting } \\
\text { AEs }\end{array}$} \\
\hline & $\begin{array}{c}\text { Crohn's } \\
\text { disease } \\
{[\mathrm{n}=\mathbf{3 7 , 6 6 2}]}\end{array}$ & $\begin{array}{c}\text { Ulcerative } \\
\text { colitis } \\
{[\mathrm{n}=\mathbf{3 4 , 2 5 9 ]}}\end{array}$ & $\begin{array}{c}\text { Crohn's } \\
\text { disease } \\
{[\mathrm{n}=14,191]}\end{array}$ & $\begin{array}{c}\text { Ulcerative } \\
\text { colitis } \\
{[\mathrm{n}=\mathbf{1 4 , 0 4 2}]}\end{array}$ \\
\hline \multicolumn{5}{|l|}{ Sex, $n[\%]$} \\
\hline Female & $24,092[64]$ & $18,299[53]$ & $8511[60]$ & $7016[50]$ \\
\hline Male & $12,900[34]$ & $15,457[45]$ & $5260[37]$ & $6729[48]$ \\
\hline Not reported & $670[2]$ & $503[1]$ & $420[3]$ & $297[2]$ \\
\hline \multicolumn{5}{|l|}{ Age, years $\mathrm{n}[\%]^{\mathrm{a}}$} \\
\hline$<70$ years & $31,439[83]$ & $28,973[85]$ & $11,345[80]$ & $11,580[82]$ \\
\hline$\geq 70$ years & $2934[8]$ & $3050[9]$ & $1065[8]$ & $1153[8]$ \\
\hline Not reported & $3289[9]$ & $2236[7]$ & $1781[13]$ & $1309[9]$ \\
\hline \multicolumn{5}{|l|}{ Prior anti-TNF $\alpha$ therapy, $\mathrm{n}[\%]$} \\
\hline Yes & $21,145[56]$ & $17,749[52]$ & $7286[51]$ & $6740[48]$ \\
\hline No & $5986[16]$ & $8627[25]$ & $2232[16]$ & $3530[25]$ \\
\hline No prior medication reported at all & $10,531[28]$ & $7883[23]$ & $4673[33]$ & $3772[27]$ \\
\hline \multicolumn{5}{|l|}{ Concomitant anti-TNF $\alpha$ therapy, $\mathrm{n}[\%]$} \\
\hline Yes & $908[2]$ & $1305[4]$ & $343[2]$ & $521[4]$ \\
\hline No & $26,306[70]$ & $26,330[77]$ & 8978 [63] & $10,135[72]$ \\
\hline \multicolumn{5}{|l|}{ Other concomitant immunosuppressant, $\mathrm{n}[\%]$} \\
\hline Yes & $6344[17]$ & $6535[19]$ & $2243[16]$ & $2566[18]$ \\
\hline No & $20,870[55]$ & $21,100[62]$ & $7078[50]$ & $8090[58]$ \\
\hline \multicolumn{5}{|l|}{ Concomitant corticosteroid, $\mathrm{n}[\%]$} \\
\hline Yes & $11,720[31]$ & $15,405[45]$ & $3943[28]$ & $5958[42]$ \\
\hline No & $15,494[41]$ & $12,230[36]$ & $5378[38]$ & 4698 [33] \\
\hline No concomitant medication reported at all, $\mathrm{n}[\%]$ & $10,448[28]$ & $6624[19]$ & $4870[34]$ & $3386[24]$ \\
\hline
\end{tabular}

${ }^{a}$ Vedolizumab is not approved in patients $<18$ years of age.

$\mathrm{AE}$, adverse event; TNF $\alpha$, tumour necrosis factor alpha. 
Table 2. Adverse events reported in patients with Crohn's disease or ulcerative colitis in the post-marketing setting stratified by age or previous anti-TNF $\alpha$ exposure.

\begin{tabular}{|c|c|c|c|c|c|c|}
\hline \multirow{2}{*}{$\begin{array}{c}\text { Category of } \\
\text { adverse event, } \\
\text { n [\%] }\end{array}$} & \multicolumn{3}{|c|}{$\begin{array}{l}\text { Total number of AEs reported in patients } \\
\text { with Crohn's disease }[\mathrm{n}=\mathbf{3 7 , 6 6 2 ]}\end{array}$} & \multicolumn{3}{|c|}{$\begin{array}{l}\text { Total number of AEs reported in patients } \\
\text { with ulcerative colitis }[\mathrm{n}=\mathbf{3 4 , 2 5 9 ]}\end{array}$} \\
\hline & $\begin{array}{c}\text { Patients aged } \\
<70 \text { years old } \\
\text { [Number of } \\
\text { AEs, } \\
\mathbf{n}=\mathbf{3 1 , 4 3 9 ]}\end{array}$ & $\begin{array}{l}\text { Patients aged } \\
\begin{array}{c}\geq 70 \text { years old } \\
\text { [Number of } \\
\text { AEs, } \\
n=2934 \text { ] }\end{array}\end{array}$ & $\begin{array}{c}\text { Age not } \\
\text { reported } \\
\text { [Number of } \\
\text { AEs, } \\
\mathbf{n}=3289]\end{array}$ & $\begin{array}{c}\text { Patients aged } \\
<70 \text { years old } \\
\text { [Number of } \\
\text { AEs, } \\
\mathbf{n}=\mathbf{2 8 , 9 7 3}]\end{array}$ & $\begin{array}{c}\text { Patients aged } \\
\begin{array}{c}\geq 70 \text { years old } \\
\text { [Number of } \\
\text { AEs, } \\
\mathbf{n}=\mathbf{3 0 5 0} \text { ] }\end{array}\end{array}$ & $\begin{array}{c}\text { Age not } \\
\text { reported } \\
\text { [Number of } \\
\text { AEs, } \\
\mathbf{n}=\mathbf{2 2 3 6}]\end{array}$ \\
\hline $\begin{array}{l}\text { GI AEs } \\
{[\mathrm{CD}, \mathrm{n}=6156 ; \mathrm{UC}, \mathrm{n}=} \\
5701]\end{array}$ & 5210 [17] & 456 [16] & 490 [15] & 4849 [17] & 511 [17] & 341 [15] \\
\hline $\begin{array}{l}\text { Malignancies } \\
{[\mathrm{CD}, \mathrm{n}=134 ; \mathrm{UC}, \mathrm{n}=} \\
117]\end{array}$ & $96[<1]$ & $21[<1]$ & $17[<1]$ & $76[<1]$ & $24[<1]$ & $17[<1]$ \\
\hline $\begin{array}{l}\text { Hepatobiliary AEs } \\
{[\mathrm{CD}, \mathrm{n}=186 ; \mathrm{UC}, \mathrm{n}=} \\
216]\end{array}$ & $154[<1]$ & $15[<1]$ & $17[<1]$ & $173[<1]$ & $7[<1]$ & 36 [2] \\
\hline $\begin{array}{l}\text { Infections } \\
{[\mathrm{CD}, \mathrm{n}=3064 ; \mathrm{UC}, \mathrm{n}=} \\
2812]\end{array}$ & 2631 [8] & $228[8]$ & 205 [6] & $2420[8]$ & $233[8]$ & 159 [7] \\
\hline $\begin{array}{l}\text { Serious infections } \\
{[\mathrm{CD}, \mathrm{n}=710 ; \mathrm{UC}, \mathrm{n}=} \\
427]\end{array}$ & $572[2]$ & $67[2]$ & $71[2]$ & 317 [1] & 59 [2] & 51 [2] \\
\hline $\begin{array}{l}\text { Opportunistic } \\
\text { infections }[\mathrm{CD}, \mathrm{n}= \\
100 ; \mathrm{UC}, \mathrm{n}=201]\end{array}$ & $75[<1]$ & $14[<1]$ & $11[<1]$ & $159[<1]$ & $21[<1]$ & $21[<1]$ \\
\hline $\begin{array}{c}\text { Anti-TNF } \alpha \\
\text { therapy } \\
\text { Category of } \\
\text { adverse event, } n \\
\text { [\%] }\end{array}$ & $\begin{array}{c}\text { Previous } \\
\text { exposure to } \\
\text { anti-TNF } \alpha \\
\text { therapy }\end{array}$ & $\begin{array}{l}\text { No previous } \\
\text { exposure to } \\
\text { anti-TNF } \alpha \\
\text { therapy }\end{array}$ & $\begin{array}{c}\text { No prior } \\
\text { medication } \\
\text { reported at } \\
\text { all }\end{array}$ & $\begin{array}{c}\text { Previous } \\
\text { exposure to } \\
\text { anti-TNF } \alpha \\
\text { therapy }\end{array}$ & $\begin{array}{l}\text { No previous } \\
\text { exposure to } \\
\text { anti-TNF } \alpha \\
\text { therapy }\end{array}$ & $\begin{array}{c}\text { No prior } \\
\text { medication } \\
\text { reported at } \\
\text { all }\end{array}$ \\
\hline
\end{tabular}




\begin{tabular}{|c|c|c|c|c|c|c|}
\hline & $\begin{array}{c}\text { [Number of } \\
\text { AEs, } \\
\mathrm{n}=\mathbf{2 1 , 1 4 5 ]}\end{array}$ & $\begin{array}{c}\text { [Number of } \\
\text { AEs, } \\
\text { n = 5986] }\end{array}$ & 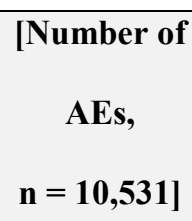 & 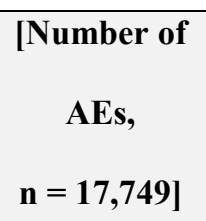 & $\begin{array}{c}\text { [Number of } \\
\text { AEs, } \\
\mathbf{n}=8627]\end{array}$ & $\begin{array}{c}\text { [Number of } \\
\text { AEs, } \\
\text { n = 7883] }\end{array}$ \\
\hline $\begin{array}{l}\text { GI AEs } \\
{[\mathrm{CD}, \mathrm{n}=6156 ; \mathrm{UC}, \mathrm{n}=} \\
5701]\end{array}$ & 3571 [17] & 1029 [17] & 1556 [15] & 3019 [17] & 1441 [17] & $1241[16]$ \\
\hline $\begin{array}{l}\text { Malignancies } \\
{[\mathrm{CD}, \mathrm{n}=134 ; \mathrm{UC}, \mathrm{n}=} \\
117]\end{array}$ & $65[<1]$ & $20[<1]$ & $49[<1]$ & $51[<1]$ & $21[<1]$ & $45[<1]$ \\
\hline $\begin{array}{l}\text { Hepatobiliary AEs } \\
{[\mathrm{CD}, \mathrm{n}=186 ; \mathrm{UC}, \mathrm{n}=} \\
216]\end{array}$ & $79[<1]$ & $43[<1]$ & $64[<1]$ & $83[<1]$ & $45[<1]$ & 88 [1] \\
\hline $\begin{array}{l}\text { Infections } \\
{[\mathrm{CD}, \mathrm{n}=3064 ; \mathrm{UC}, \mathrm{n}=} \\
2812]\end{array}$ & 1839 [9] & 488 [8] & 737 [7] & 1504 [8] & $716[8]$ & $592[8]$ \\
\hline $\begin{array}{l}\text { Serious infections } \\
{[\mathrm{CD}, \mathrm{n}=710 ; \mathrm{UC}, \mathrm{n}=} \\
427]\end{array}$ & $382[2]$ & 104 [2] & 224 [2] & 194 [1] & $79[<1]$ & 154 [2] \\
\hline $\begin{array}{l}\text { Opportunistic } \\
\text { infections [CD, } \mathrm{n}= \\
100 ; \mathrm{UC}, \mathrm{n}=201]\end{array}$ & $54[<1]$ & $13[<1]$ & $33[<1]$ & $104[<1]$ & $43[<1]$ & $54[<1]$ \\
\hline
\end{tabular}

AE, adverse event; CD, Crohn's disease; GI, gastrointestinal; TNF $\alpha$, tumour necrosis factor alpha; UC, ulcerative colitis. 
Table 3. Adverse events reported in at least $1 \%$ of pregnancy reports in the post-marketing setting. ${ }^{\text {a }}$

\begin{tabular}{|c|c|c|c|}
\hline \multicolumn{2}{|c|}{$\begin{array}{c}\text { Crohn's disease } \\
{[\text { Number of AEs, } n=912]^{b}}\end{array}$} & \multicolumn{2}{|c|}{ 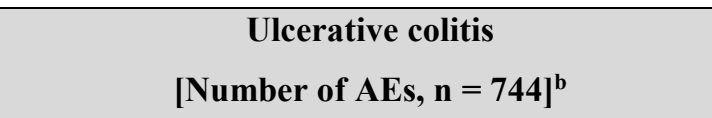 } \\
\hline Preferred term & n [\%] & Preferred term & n [\%] \\
\hline Pregnancy & $285[31]$ & Pregnancy & 215 [29] \\
\hline No adverse event $t^{\mathrm{c}}$ & $205[22]$ & No adverse event & 179 [24] \\
\hline Off-label use $^{\mathrm{c}}$ & $45[5]$ & Pregnancy of partner & $37[5]$ \\
\hline Abortion spontaneous & 29 [3] & Off-label use & $30[4]$ \\
\hline $\begin{array}{l}\text { Exposure during pregnancy; } \\
\text { pregnancy of partner }\end{array}$ & 27 [3] [each] & Exacerbation of ulcerative colitis & $23[3]$ \\
\hline Exacerbation of Crohn's disease & $23[3]$ & Abortion spontaneous & 19 [3] \\
\hline Drug ineffective ${ }^{\mathrm{c}}$ & $13[1]$ & Exposure during pregnancy & $18[2]$ \\
\hline Exposure via breast milk & $10[1]$ & Exposure via breast milk & $12[2]$ \\
\hline Abdominal pain; headache & 7 [ $<1]$ [each] & $\begin{array}{l}\text { Drug ineffective; therapeutic } \\
\text { reaction time decreased }^{c}\end{array}$ & 8 [1] [each] \\
\hline Fatigue; weight increased & $6[<1]$ [each] & $\begin{array}{l}\text { Inappropriate schedule of drug } \\
\text { administration }^{\mathrm{c}}\end{array}$ & $7[<1]$ \\
\hline $\begin{array}{l}\text { Inappropriate schedule of drug } \\
\text { administration; nasopharyngitis; } \\
\text { therapeutic reaction time } \\
\text { decreased }\end{array}$ & $5[<1]$ [each] & Nasopharyngitis & $6[<1]$ \\
\hline & & Nausea & $5[<1]$ \\
\hline & & $\begin{array}{l}\text { Blood pressure decreased; drug } \\
\text { dose omissionc; fatigue; heart } \\
\text { rate increased; sinusitis; weight } \\
\text { decreased; weight fluctuation }\end{array}$ & $4[<1][$ each $]$ \\
\hline
\end{tabular}

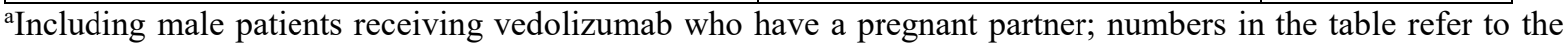
number of events.

b' $n$ ' represents the total number of AEs reported during pregnancy for an indication.

${ }^{\mathrm{c}}$ These adverse event terms are recorded for regulatory requirements.

$\mathrm{AE}$, adverse event 
Figure 1. Most frequently reported serious and non-serious AEs reported in patients with Crohn's disease or ulcerative colitis in the post-marketing setting.

Most frequently reported SAEs ${ }^{a}$

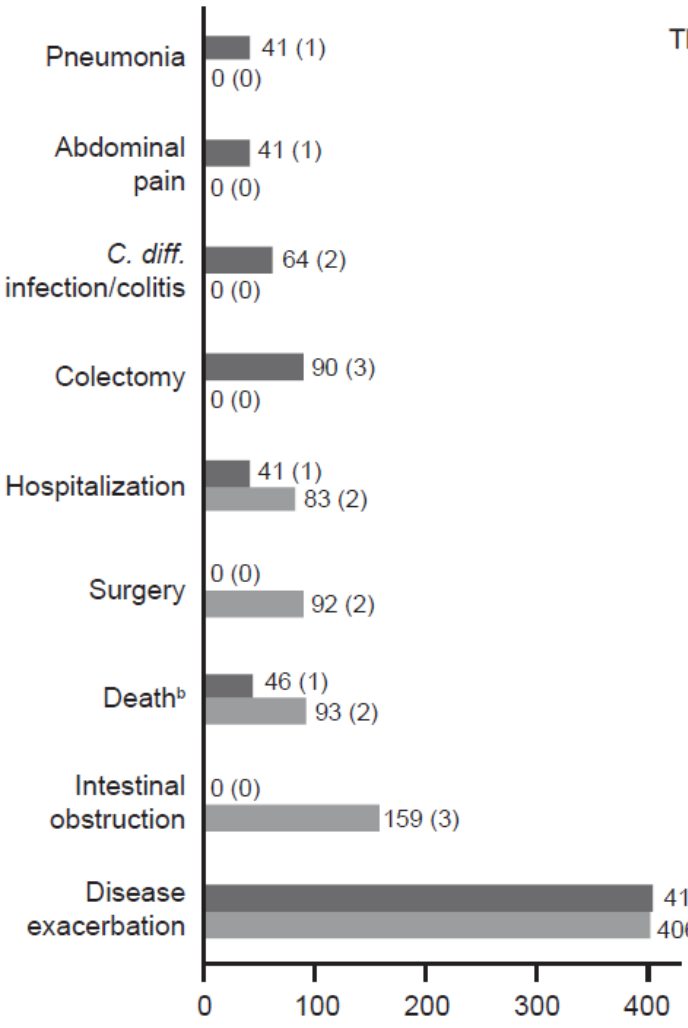

Most frequently reported non-serious AEs ${ }^{\mathrm{a}}$

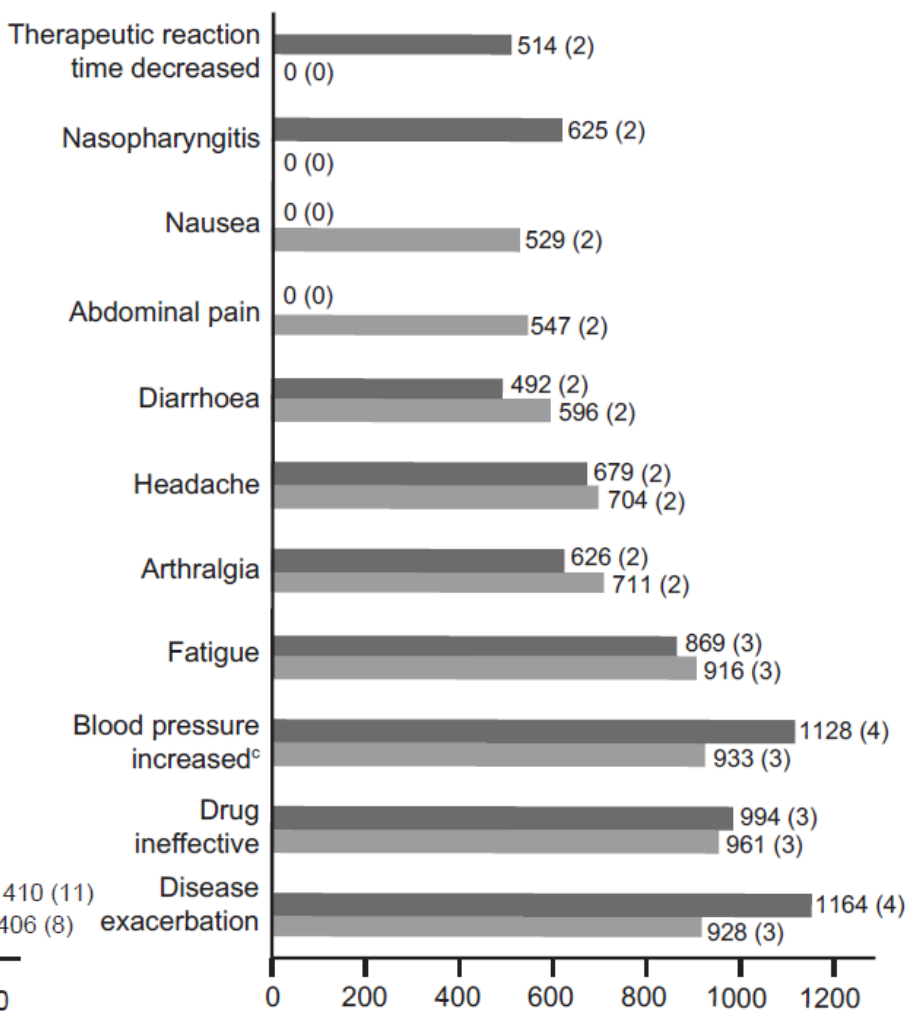

Ulcerative colitis Crohn's disease

Data are number of AEs recorded (y-axis) under the stated MedDRA preferred terms (x-axis). Values are given as $\mathrm{n}(\%)$.

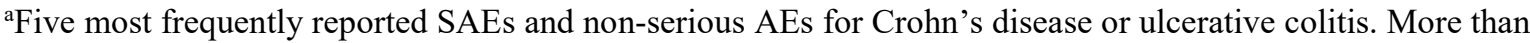
five AEs may therefore be presented. Non-serious AEs are included that accounted for $\geq 2 \%$ of reports.

b'Death' refers to reports in which the documented adverse event term was 'death', and no further information was provided. Most AE reports of 'death' arose from insurance databases and patient support programme data and were notifications that the patient died whilst receiving vedolizumab, with no additional information given. 'Increases in blood pressure were transient during infusion of vedolizumab and resolved following cessation of infusion.

AE, adverse event; MedDRA PT, Medical Dictionary for Regulatory Activities preferred term; SAE, serious AE. 
Figure 2. Most frequently reported AEs in patients with Crohn's disease or ulcerative colitis in the post-marketing setting. ${ }^{\text {a }}$
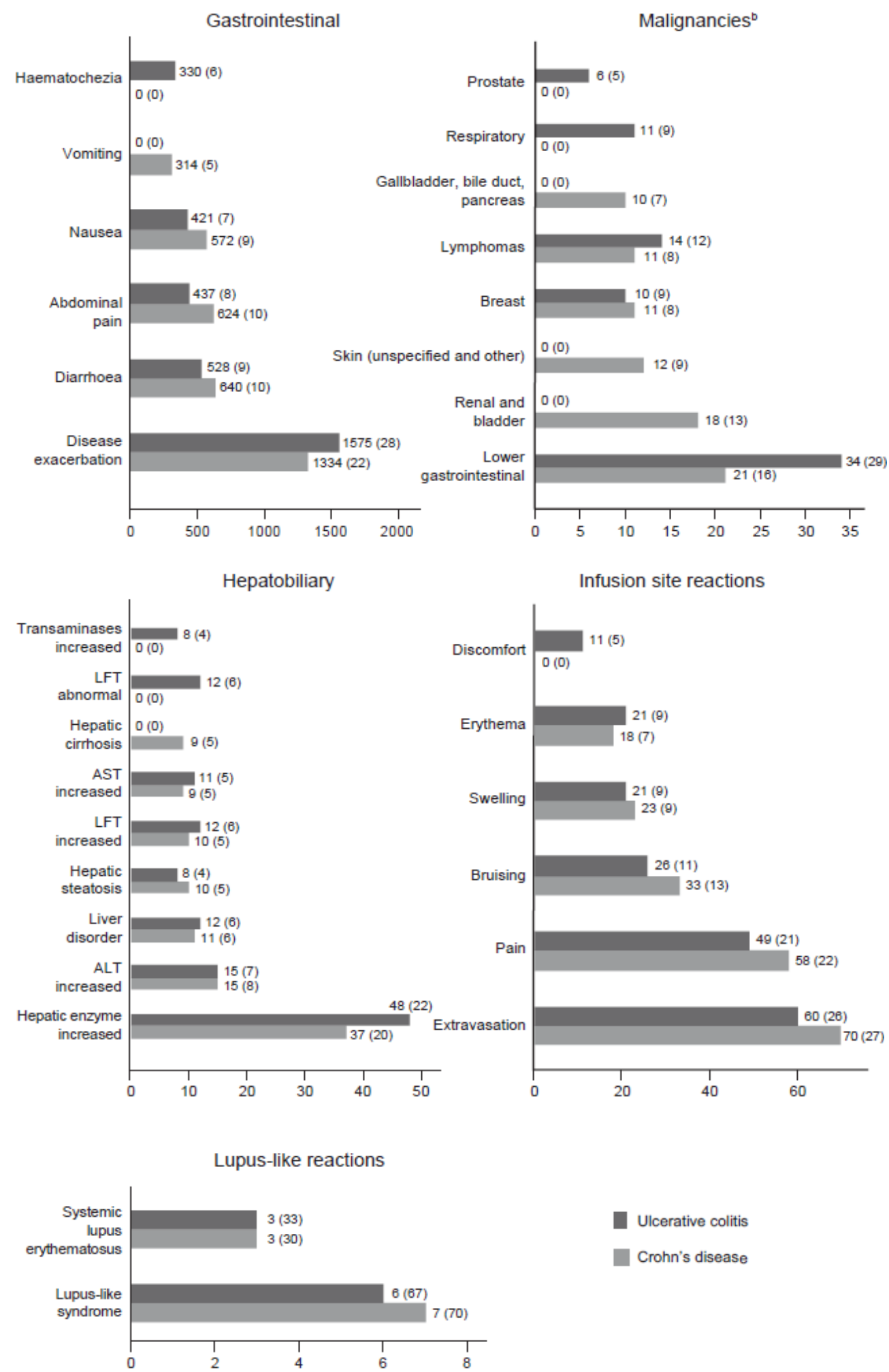

Data are number of AEs recorded (y-axis) under the stated MedDRA preferred terms (x-axis). Values are given as $\mathrm{n}(\%)$. 
aFive most frequently reported AEs for Crohn's disease or ulcerative colitis. More than five AEs may therefore be presented.

${ }^{\mathrm{b}}$ Reports of malignancies were identified using Medical Dictionary for Regulatory Activities version 21.0 'Neoplasms benign, malignant and unspecified [including cysts and polyps]' system organ class. Reports of benign neoplasms, colon adenomas, non-melanoma skin cancers and pre-treatment events were excluded. AE, adverse event; ALT, alanine aminotransferase; AST, aspartate aminotransferase; LFT, liver function tests. 
Figure 3. Most frequently reported infections reported in patients with Crohn's disease or ulcerative colitis in the post-marketing setting.

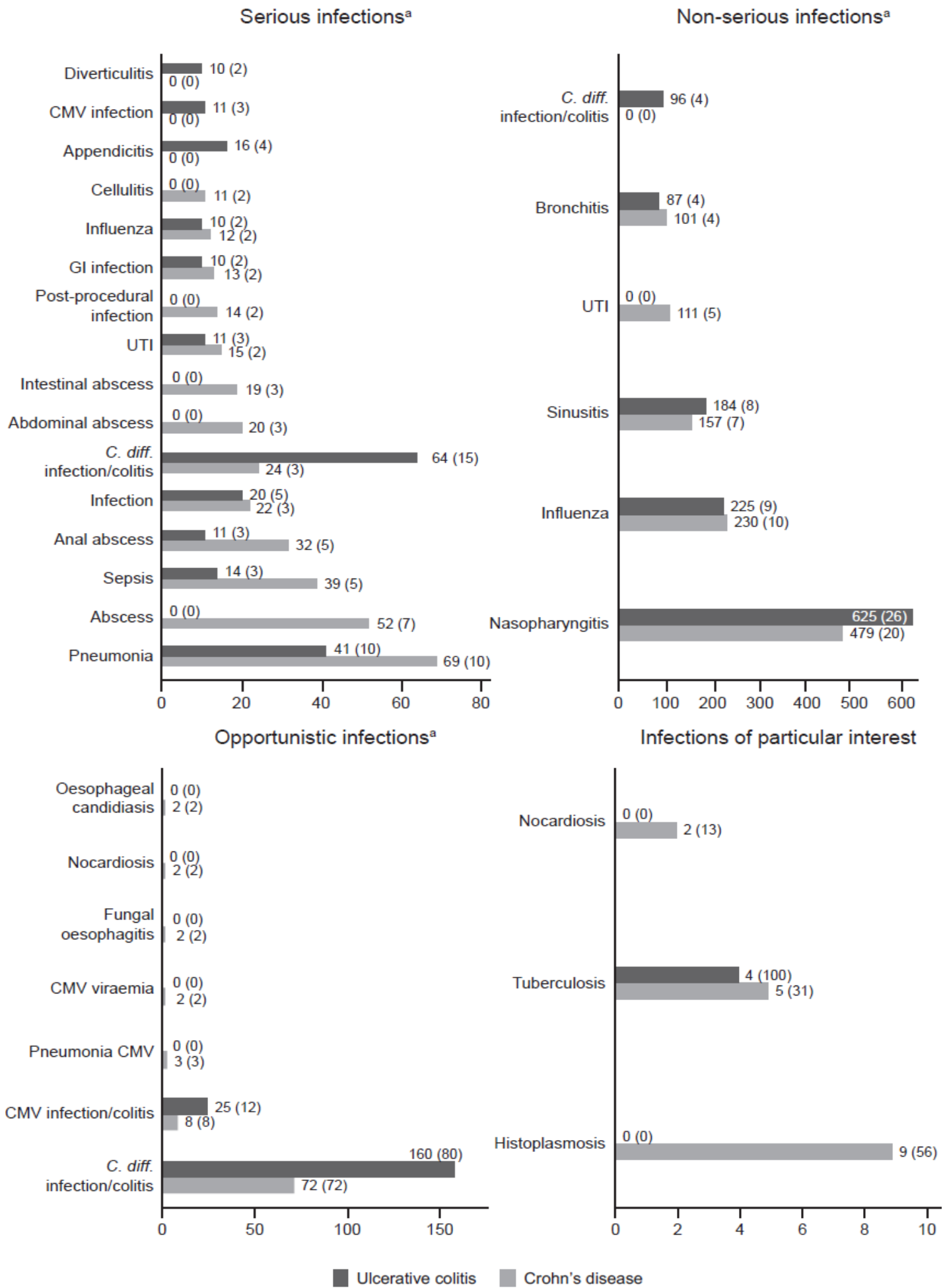

Data are number of AEs recorded (y-axis) under the stated MedDRA preferred terms (x-axis). Values are given as $\mathrm{n}(\%)$.

${ }^{\text {a}}$ Five most frequently reported AEs for Crohn's disease or ulcerative colitis. More than five AEs may therefore be presented. Serious and opportunistic infections are included that accounted for $\geq 2 \%$ of reports. 
AE, adverse event; C. Diff., Clostridium difficile; CMV, cytomegalovirus; GI, gastrointestinal; MedDRA PT, Medical Dictionary for Regulatory Activities preferred term, UTI, urinary tract infection 
1 Figure 4. Outcomes of adverse events reported in the post-marketing setting in patients with Crohn's disease and ulcerative colitis.

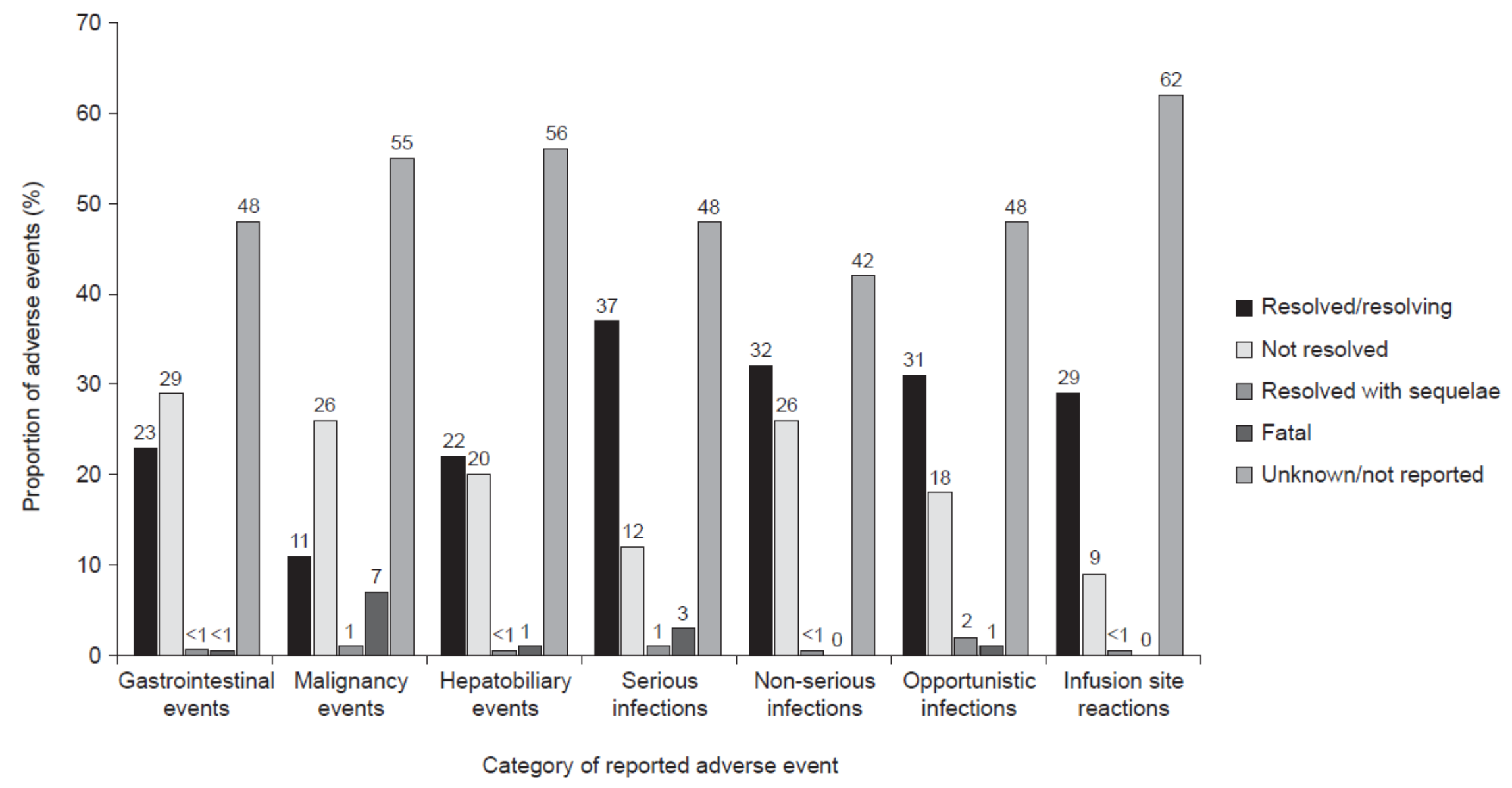


4 Figure 5. Impact of the adverse events reported in the post-marketing setting on vedolizumab treatment continuation in patients with Crohn's

5 disease and ulcerative colitis.

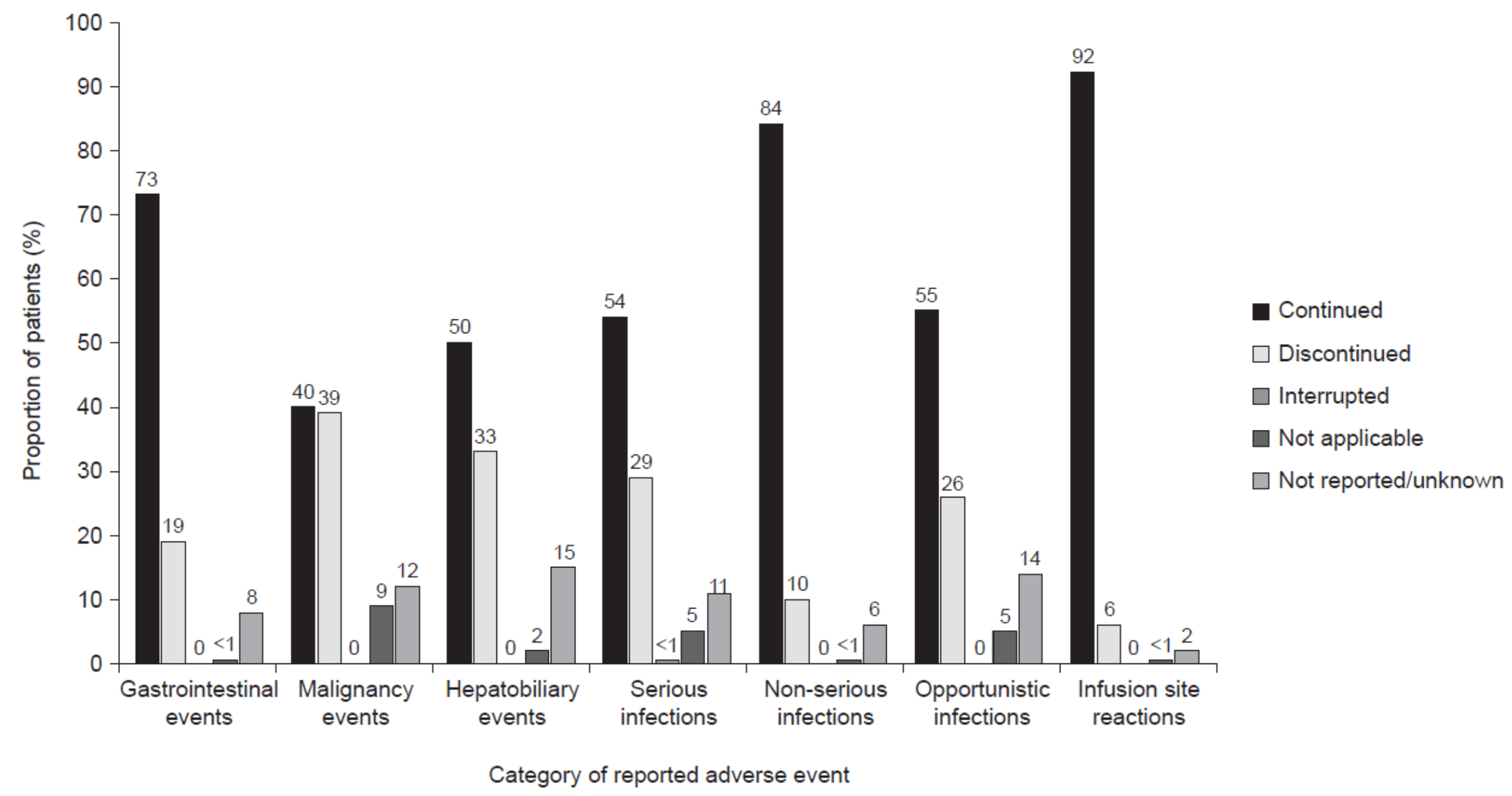

Figure 5 shows vedolizumab treatment dose/schedule continuation at the time of reporting. 